\title{
Enhancers and attenuators of risk associations of chronic hepatitis B virus infection with hepatocellular carcinoma in type 2 diabetes
}

\author{
Xilin Yang ${ }^{1,4}$, Ying Wang ${ }^{1,2}$, Andrea O Y Luk ${ }^{1,2}$, Wing Yee So ${ }^{1,2,3}$, Ronald C W Ma, ${ }^{1,2,3}$, \\ Alice P S Kong ${ }^{1,2,3}$, Gang Xu ${ }^{1,2,3}$ and Juliana C N Chan ${ }^{1,2,3}$ \\ ${ }^{1}$ Department of Medicine and Therapeutics ${ }^{2}$ Hong Kong Institute of Diabetes and Obesity ${ }^{3} \mathrm{Li}$ Ka Shing Institute of \\ Health Sciences, Prince of Wales Hospital, The Chinese University of Hong Kong, Shatin, Hong Kong SAR, China \\ ${ }^{4}$ Department of Epidemiology and Biostatistics, School of Public Health, Tianjin Medical University, 22 Qixiangtai \\ Road, PO Box 154, Heping, Tianjin 300070, China
}

Correspondence should be addressed to X Yang or J C N Chan Email yxl@hotmail.com or jchan@cuhk.edu.hk

\begin{abstract}
Chronic hepatitis B virus (HBV) infection promotes hepatocellular carcinoma (HCC) risk. In type 2 diabetes (T2D), use of insulin and statins was associated with reduced cancer risk while co-presence of low $\mathrm{LDL}$ cholesterol ( $\mathrm{LDLC}<2.8 \mathrm{mmol} / \mathrm{l}$ ) plus low triglyceride (TG; $<1.7 \mathrm{mmol} / \mathrm{l})$ increased cancer risk. There is experimental evidence showing that insulin insufficiency might promote HCC. In this study, we examined whether this lipid subphenotype and use of insulin or statins might modify the promoting effect of chronic HBV infection (indicated by the presence of hepatitis B surface antigen) on HCC. We analyzed data of 1319 T2D patients enrolled into the Hong Kong Diabetes Registry from December 1996 to January 2005 and followed up to 2005. Additive interaction was estimated using relative excess risk due to interaction and attributable proportion due to interaction. During 5782 person-years of follow-up, 1.74\% $(n=23)$ of patients developed HCC (incidence, 3.98; $95 \%$ confidence interval, $2.36-5.60 / 1000$ person-years). HbA1c $\geq 7.0 \%$ and the lipid phenotype (LDLC $<2.8 \mathrm{mmol} / \mathrm{l}$ plus TG $<1.7 \mathrm{mmol} / \mathrm{l}$ ) increased the hazard ratios (HRs) of chronic HBV infection for HCC from 3.74 to 74.96 and from 11.01 to 89.82 respectively with significant interactions. Use of insulin or statins decreased the HRs from 37.51 to 5.87 and from 64.94 to 16.99 respectively with significant interactions (all $P$ values $<0.05$ ). These findings support our hypothesis that hyperglycemia and co-presence of low LDLC plus low TG might enhance, while insulin or statin usage might attenuate the promoting effect of chronic HBV infection on HCC in T2D.
\end{abstract}

\footnotetext{
Key Words

- HBsAg

- liver cancer

- low LDL cholesterol

- low triglyceride

- hyperglycemia

- additive interaction

- HbA1c
}

\section{Introduction}

Diabetes is a global epidemic with rapid increase in Asia (Chan et al. 2009). In China, 9.7\% of adult men and women had diabetes in 2007-2008 (Yang et al. 2010b). Apart from lifestyle changes, many developing areas are undergoing rapid transition from communicable to noncommunicable disease. In China, 7\% of people have chronic hepatitis B virus (HBV) infection as indicated by positive hepatitis B surface antigen (HBsAg) (Wang \& Jia 2011). 
The latter is a major promoter of hepatocellular carcinoma (HCC), which is one of the most prevalent cancers with poor prognosis (Burrel et al. 2012, Forner et al. 2012). Diabetes is associated with increased risk of a spectrum of cancers (Yang et al. 2012b) with a linear relationship between HbA1c and all-site cancer risk (Yang et al. 2010a). In most surveys, among site-specific cancers, HCC ranks second in terms of strength of association with diabetes (El-Serag et al. 2006), only preceded by pancreatic cancer (Everhart \& Wright 1995).

Using the Hong Kong Diabetes Registry, we reported a series of drug-subphenotype interactions, based on which we put forth an integrated hypothesis, supported by results from mechanistic studies, to explain the biological links between type 2 diabetes (T2D) and cancer (Yang et al. 2012b). These included i) downregulation of the adenosine $5^{\prime}$-monophosphate-activated protein kinase (AMPK) pathway suggested by the attenuated cancer risk in metformin users with low HDL cholesterol (HDLC $<1.0 \mathrm{mmol} / \mathrm{l}$; Yang et al. 2011b); ii) activation of the renin-angiotensin system (RAS) and low-grade inflammation suggested by the attenuated cancer risk in RAS inhibitor users with high white blood cell count (WBC $\geq 8.2 \times 10^{9} /$; Y Yang et al. 2010 c); iii) activation of the RAS and dysregulation of cholesterol metabolism suggested by the attenuated cancer risk in statin users with co-presence of low LDL cholesterol (LDLC; $<2.8 \mathrm{mmol} / \mathrm{l}$ ) plus albuminuria (Yang et al. 2009a) with possible cross talks between the RAS and lipid metabolism (Yang et al. 2009b); and iv) insulin insufficiency with dysregulation of the insulin-like growth factor 1 (IGF1) and the cholesterol synthesis pathway via the sterol regulatory binding protein 1 (SREBP1), suggested by a synergistic effect of triglyceride (TG) $<1.7 \mathrm{mmol} / \mathrm{l}$ and LDLC $<2.8 \mathrm{mmol} / \mathrm{l}$ for cancer (Yang et al. 2012a) and attenuated cancer risk in statin users with TG $<1.7 \mathrm{mmol} / \mathrm{l}$ (Yang et al. 2011a).

In an experimental study reported by Japanese workers, compared with insulin-sufficient tumor-prone mice, insulin-deficient and hyperglycemic animals had an increased number and size of liver tumors with reduced apoptosis. Intriguingly, insulin therapy reduced the number and size of liver tumors with increased apoptosis (Yamasaki et al. 2010). These findings strongly suggested that either hyperglycemia or lack of insulin or both might play a causal role in promoting HCC development in diabetes. In a large cohort of HBV carriers with an accrual of 1021 HCC events during 328946 person-years of follow-up, statin use was associated with reduced risk of HCC in a dose-effect manner with $66 \%$ risk reduction in subjects using high-dose statins (Tsan et al. 2012).
Results from these two studies corroborated our hypothesis regarding the role of insulin insufficiency and dysregulated lipid metabolism in linking diabetes and cancer including HCC.

As HBV infection is a well-established risk factor for HCC (De Mitri et al. 2010), we further tested this hypothesis by examining i) the enhancing effects of insulin insufficiency reflected by $\mathrm{HbA} 1 \mathrm{c} \geq 7 \%$ and copresence of TG $<1.7 \mathrm{mmol} / \mathrm{l}$ plus LDLC $<2.8 \mathrm{mmol} / \mathrm{l}$ and ii) attenuating effects of use of insulin and statins, on the risk association between HBV infection and HCC, if any.

\section{Patients and methods}

\section{Patients}

The Hong Kong Diabetes Registry was established at the Prince of Wales Hospital affiliated to the Chinese University of Hong Kong in 1995 as a quality improvement program. It enrolled 30-50 ambulatory diabetic patients weekly, referred from general practitioners as well as community- and hospital-based clinics. Among the enrolled patients, $10 \%$ or fewer had hospital admissions within 6-8 weeks before the assessment. At enrollment, a 4-h assessment of complications and risk factors was performed on an outpatient basis using standard procedures modified from the European DiabCare protocol (Piwernetz et al. 1993). Once a diabetic subject had undergone this comprehensive assessment, they were considered to have entered this study cohort and would be observed until death.

Hong Kong maintains a highly subsidized health care system. The Hospital Authority (HA) is the governing body of all public-funded hospitals and outpatient clinics, which provides $95 \%$ of the total hospital bed-days and $80 \%$ of the outpatient visits (Yang et al. 2008b). All patients admitted to HA hospitals or followed at HA hospital clinics were dispensed medications on site. These drug-dispensing data were computerized in the HA Central Computer System since 1 December 1996. We retrieved the dispensing data of drugs of interest from 1 December to 30 July 2005, the censoring date of this study. Discharge diagnoses of hospital admissions and mortality during this period were retrieved from the HA Central Computer System to define clinical endpoints. These databases were successfully matched by a unique identification number, the Hong Kong Identity Card number, which is compulsory for all residents in Hong Kong, and used by all government departments and major organizations. Ethical approval was obtained

Published by Bioscientifica Ltd 
from the Chinese University of Hong Kong Clinical Research Ethics Committee and informed consent was obtained from all patients for research purposes.

From December 1996 to January 2005, 7387 diabetic patients were enrolled in this registry. We sequentially excluded 323 patients with T1D defined as acute presentation with ketoacidosis, heavy ketonuria $(>3+)$, or continuous requirement of insulin within 1 year of diagnosis (Laakso \& Pyorala 1985) and five with uncertain T1D status, 45 with non-Chinese or unknown nationality, and 175 patients with history of cancer or on cancer treatment documented at enrollment. In addition, 732 patients with missing values on variables used in the analysis were excluded. In the remaining 6107 patients, 1319 patients had HBsAg measurement data and were included in the analysis.

\section{The endpoint}

A team of trained personnel at the HA routinely coded all hospital discharge principal diagnoses according to the International Classification of Diseases, Ninth Revision (ICD9). ICD9 codes were used to identify first admissions due to HCC, defined as having a first HCC during the follow-up period (Code 155).

\section{Clinical and laboratory measurements}

At enrollment, patients underwent a 4-h comprehensive screening for complications and other risk factors after at least $8 \mathrm{~h}$ of fasting without taking any medication (Yang et al. 2008b). BMI was measured in subjects wearing light clothing and without shoes. Sitting blood pressure (BP) was measured after at least 5 min of rest using Dinamapp machine. The abbreviated Modification of Diet in Renal Disease formula recalibrated for Chinese (Ma et al. 2006) was used to estimate glomerular filtration rate (eGFR) expressed in $\mathrm{ml} / \mathrm{min}$ per 1.73 per $\mathrm{m}^{2}$ : eGFR $=186$ $\times(\mathrm{SCR} \times 0.011)^{-1.154} \times(\text { age })^{-0.203} \times(0.742$ if female or 1 if male) $\times 1.233$, where SCR was serum creatinine expressed as $\mu \mathrm{mol} / \mathrm{l}$ (original $\mathrm{mg} / \mathrm{dl}$ converted to $\mu \mathrm{mol} / \mathrm{l}$ ) and 1.233 is the adjusting coefficient for Chinese. Plasma glucose was measured by a hexokinase method (Hitachi 911 automated analyzer, Boehringer Mannheim, Mannheim, Germany). HbA1c was measured by an automated ion-exchange chromatographic method (BioRad Diamat HbA1c analyzer, Bio-Rad Laboratory with reference range: 5.1-6.4\%). Both interassay and intra-assay coefficients of variation (CV) for HbA1c were $\leq 3.1 \%$ at values below $6.5 \%$. Total cholesterol, TG, and HDLC were measured by enzymatic methods on a Hitachi 911 automated analyzer (Boehringer Mannheim) using reagent kits supplied by the manufacturer of the analyzer. LDLC was calculated by Friedewald's equation (Friedewald et al. 1972). Spot urinary creatinine (Jaffe's kinetic method) and albumin (immunoturbidimetry method) were also measured on the Hitachi 911 analyzer using reagent kits supplied by the manufacturer. The interassay $\mathrm{CV}$ were 12.0 and $2.3 \%$ for urinary albumin concentrations of 8.0 and $68.8 \mathrm{mg} / \mathrm{l}$, respectively. The lowest detection limit was $3.0 \mathrm{mg} / \mathrm{l}$. Albuminuria was defined as urinary albumin to creatinine ratio $\geq 2.5 \mathrm{mg} / \mathrm{mmol}$ in male and $\geq 3.5 \mathrm{mg} / \mathrm{mmol}$ in female. HBsAg was tested using commercially available ELISA kits (Abbott GmbH Diagnostika).

\section{Statistical analyses}

The Statistical Analysis System (release 9.10) was used to perform the statistical analysis (SAS Institute, Inc., Cary, NC, USA). Cox proportional hazard analysis was used to obtain hazard ratio (HR) and 95\% confidence interval (95\% CI) of predictors for HCC. Follow-up time was calculated as the period from enrollment to the date of first admission for HCC, death, or 30th July 2005, whichever came first.

We defined HbA1c $\geq 7.0 \%$ as suboptimal glycemic control (American Diabetes Association 2012) and tested its additive interaction with chronic HBV infection, defined by the presence of HBsAg, on risk of HCC. Our previous analysis showed that co-presence of LDLC $<2.80 \mathrm{mmol} / \mathrm{l}$ and TG $<1.70 \mathrm{mmol} / \mathrm{l}$ (Yang et al. 2012a) and that of LDLC $<2.8 \mathrm{mmol} / \mathrm{l}$ and albuminuria (Yang et al. 2009a) had synergistic effects on cancer risk and thus were coded as two new variables (yes/no). We also tested whether these interactions would modify the effect size of HBV infection on the risk of HCC. Relative excess risk due to interaction (RERI) and attributable proportion due to interaction (AP) (Andersson et al. 2005, Li \& Chambless 2007) were used to estimate additive interaction of HBV infection with other factors. RERI was the excess risk due to interaction relative to the risk without exposure. AP was referred to the attributable proportion of disease due to interaction in persons with both exposures. RERI $>0$ or AP $>0$ indicated a significant additive interaction. A significant interaction between a factor and HBV infection for HCC suggests that the factor enhances the effect of HBV infection on HCC risk. For use of insulin and statins, we coded nonuse of these drugs as risk factors. Thus, a significant additive interaction between HBV infection and nonuse of a drug suggests that use of the drug might attenuate the effect of HBV infection on HCC risk.

Published by Bioscientifica Ltd. 
Table 1 Clinical and biochemical characteristics of the study cohort stratified according to availability of HBsAg status.

\begin{tabular}{|c|c|c|c|}
\hline & HBsAg status not available $(n=4784)$ & HBsAg status available $(n=1319)$ & \\
\hline & Median (25th-75th) or \% (n) & Median (25th-75th) or \% $(n)$ & $P$ value ${ }^{a}$ \\
\hline \multicolumn{4}{|l|}{ Baseline variables } \\
\hline Age (years) & $57(47-67)$ & $58(48-68)$ & 0.1960 \\
\hline Duration of diabetes (years) & $6(2-11)$ & $7(2-12)$ & 0.1888 \\
\hline Gender (male) & $43.6 \%(2087)$ & $54.7 \%(721)$ & $<0.0001$ \\
\hline Smoking status & & & $<0.0001$ \\
\hline Ex-smoker & $14.2 \%(679)$ & $19.5 \%(257)$ & \\
\hline Current smoker & $14.8 \%(707)$ & $16.5 \%(218)$ & \\
\hline Alcohol intake & & & $<0.0001$ \\
\hline Ex-drinker & $11.2 \%(535)$ & $15.9 \%(210)$ & \\
\hline Current drinker & $7.5 \%(358)$ & $6.8 \%(89)$ & \\
\hline BMI $\left(\mathrm{kg} / \mathrm{m}^{2}\right)$ & $24.7(22.4-27.3)$ & $25.0(22.7-27.9)$ & 0.0019 \\
\hline Systolic BP $(\mathrm{mmHg})$ & $134(121-148)$ & $136(124-151)$ & 0.0029 \\
\hline Diastolic BP (mmHg) & $75(68-82)$ & $75(68-80)$ & 0.8432 \\
\hline $\mathrm{HbA1c}(\%)$ & $7.2(6.3-8.3)$ & $7.5(6.5-8.7)$ & $<0.0001$ \\
\hline $\mathrm{HDLC}(\mathrm{mmol} / \mathrm{l})$ & $1.27(1.07-1.51)$ & $1.29(1.07-1.52)$ & 0.0034 \\
\hline LDLC (mmol/l) & $3.12(2.50-3.80)$ & $3.10(2.47-3.80)$ & 0.0376 \\
\hline Triglyceride (mmol/l) & $1.31(0.93-1.91)$ & $1.40(1.00-2.09)$ & 0.0015 \\
\hline ACR $(\mathrm{mg} / \mathrm{mmol})$ & $1.83(0.73-8.28)$ & $4.37(1.02-47.97)$ & $<0.0001$ \\
\hline eGFR $\left(\mathrm{ml} / \mathrm{min}\right.$ per 1.73 per $\left.\mathrm{m}^{2}\right)$ & $104.6(85.5-125.5)$ & $95.7(69.3-117.9)$ & $<0.0001$ \\
\hline \multicolumn{4}{|l|}{ Medications during follow-up ${ }^{\mathrm{b}}$} \\
\hline Statins & $35.0 \%(1672)$ & $49.0 \%(646)$ & $<0.0001$ \\
\hline ACEIs/ARBs & $55.0 \%(2631)$ & $68.8 \%(970)$ & $<0.0001$ \\
\hline Insulin & $33.3 \%(1591)$ & $56.3 \%(742)$ & $<0.0001$ \\
\hline Metformin & $76.5 \%(3660)$ & $68.3 \%(901)$ & $<0.0001$ \\
\hline Gliclazide/glibenclamide & $65.1 \%(3212)$ & $60.4 \%(797)$ & 0.0019 \\
\hline Rosiglitazone/pioglitazone & $6.7 \%(321)$ & $8.95 \%(118)$ & 0.0054 \\
\hline \multicolumn{4}{|l|}{ Events during follow-up } \\
\hline Hepatocellular carcinoma & $0.33 \%(16)$ & $1.74 \%(23)$ & $<0.0001$ \\
\hline Death & $6.3 \%(302)$ & $15.4 \%(203)$ & $<0.0001$ \\
\hline \multicolumn{4}{|l|}{ Cirrhosis } \\
\hline At baseline & $0.0 \%(1)$ & $0.1 \%(1)$ & 0.3856 \\
\hline During follow-up & $0.4 \%(18)$ & $1.6 \%(21)$ & $<0.0001$ \\
\hline Either of them & $0.4 \%(19)$ & $1.7 \%(22)$ & $<0.0001$ \\
\hline
\end{tabular}

LDLC, LDL cholesterol; HDLC, HDL cholesterol; BP, blood pressure; ACR, spot urine albumin:creatinine ratio; eGFR, estimated glomerular filtration rate; ACEIs, angiotensin-converting enzyme inhibitors; $A R B s$, angiotensin II receptor blockers; HBsAg, hepatitis $B$ surface antigen.

a Kolmogorov-Smirnov two-sample test or $\chi^{2}$ test was used to test differences in distribution between the two groups.

${ }^{\mathrm{b}}$ Drug use during follow-up was defined as drug use in the period from enrollment to the first liver cancer event, death, or 30 July 2005 , whichever came first.

A two-step scheme was used to adjust for covariates. First, we used a minimum adjustment scheme that included only age, sex, BMI $\left(<24.0\right.$ and $\geq 27.6 \mathrm{~kg} / \mathrm{m}^{2}$ due to nonlinear risk association; Yang et al. 2008a), use of alcohol and tobacco, and cirrhosis at enrollment or during follow-up. Secondly, we adjusted for HbA1c (Yang et al. $2010 a, b)$, systolic BP and risk factors in T2D for cancer that showed nonlinear relationships with cancer. These risk factors included LDLC-related risk indicators (LDLC $<2.80 \mathrm{mmol} / \mathrm{l}$ plus TG $<1.7 \mathrm{mmol} / \mathrm{l}$, LDLC $<2.80 \mathrm{mmol} / \mathrm{l}$ plus albuminuria, LDLC $\geq 3.80 \mathrm{mmol} / \mathrm{l}$; Yang et al. 2012b) and HDL-cholesterol-related risk indicators (HDLC $<1.0$ and $\geq 1.30 \mathrm{mmol} / \mathrm{l}$; Yang et al. 2011b). In addition, we adjusted for use of insulin (Yang et al. 2010a), metformin (Yang et al. 2011b), RAS inhibitors (Yang et al. 2009b,

http://erc.endocrinology-journals.org DOI: 10.1530/ERC-12-0290

C) 2013 Society for Endocrinology Printed in Great Britain 2010c), gliclazide/glibenclamide (Yang et al. 2010d), and rosiglitazone/pioglitazone during follow-up (Yang et al. 2012c), which was defined as use of the drug from enrollment to the earliest date of HCC, death, or 30 July 2005, whichever came first.

In our review of major biases of pharmacoepidemiological analysis in nonclinical trial setting, we demonstrated that time-fixed Cox model analysis with exclusion of prevalent users and adjustment for drug use indication was free of major biases and could reproduce the effect of a drug as reported in clinical trials (Yang et al. $2012 d$ ). Thus, when we tested the additive interaction of HBV infection with nonuse of drugs, we excluded subjects ever exposed to the drug during the 2.5 years before enrollment (Yang et al. 2011b). Propensity scores for use of

Published by Bioscientifica Ltd 
Table 2 Clinical and biochemical characteristics of the study cohort stratified by the status of chronic HBV infection indicated by positive HBsAg.

\begin{tabular}{|c|c|c|c|}
\hline & HBsAg negative $(n=1115)$ & HBsAg positive $(n=204)$ & \\
\hline & Median (25th-75th) or \% $(n)$ & Median (25th-75th) or $\%(n)$ & $P$ value \\
\hline \multicolumn{4}{|l|}{ Baseline variables } \\
\hline Age (years) & $59(48-69)$ & $52(46-62)$ & $<0.0001$ \\
\hline Duration of diabetes (years) & $7(2-11)$ & $5(1-10)$ & 0.0233 \\
\hline Gender (male) & $52.0 \%(580)$ & $69.1 \%(141)$ & $<0.0001$ \\
\hline Smoking status & & & 0.1942 \\
\hline Ex-smoker & $19.4 \%(216)$ & $20.1 \%(41)$ & \\
\hline Current smoker & $15.8 \%(176)$ & $20.6 \%(42)$ & \\
\hline Alcohol intake & & & 0.2855 \\
\hline Ex-drinker & $16.5 \%(184)$ & $12.8 \%(26)$ & \\
\hline Current drinker & $6.5 \%(72)$ & $8.3 \%(17)$ & \\
\hline BMI $\left(\mathrm{kg} / \mathrm{m}^{2}\right)$ & $25.2(22.8-28.0)$ & $24.1(22.1-27.3)$ & 0.0026 \\
\hline Systolic BP (mmHg) & $137(125-152)$ & $131(121-142)$ & $<0.0001$ \\
\hline Diastolic BP (mmHg) & $75(68-82)$ & $73(67-80)$ & 0.1290 \\
\hline $\mathrm{HbA1c}(\%)$ & $7.4(6.5-8.7)$ & $7.6(6.3-8.9)$ & 0.7806 \\
\hline $\mathrm{HbA} 1 \mathrm{c} \geq 7.0 \%$ & $62.6 \%(698)$ & $62.3 \%(127)$ & 0.9252 \\
\hline $\mathrm{HDLC}(\mathrm{mmol} / \mathrm{l})$ & $1.23(1.03-1.49)$ & $1.29(1.07-1.52)$ & 0.1106 \\
\hline LDLC (mmol/l) & $3.12(2.50-3.80)$ & $2.81(2.28-3.50)$ & 0.0003 \\
\hline Triglyceride (mmol/l) & $1.48(1.05-2.15)$ & $1.11(0.81-1.48)$ & $<0.0001$ \\
\hline LDLC $<2.8 \mathrm{mmol} / \mathrm{l}$ plus triglyceride $<1.7 \mathrm{mmol} / \mathrm{l}$ & $29.2 \%(326)$ & $43.6 \%(89)$ & $<0.0001$ \\
\hline $\mathrm{ACR}(\mathrm{mg} / \mathrm{mmol})$ & $5.48(1.15-60.79)$ & $1.84(0.57-8.85)$ & $<0.0001$ \\
\hline LDLC $<2.8 \mathrm{mmol} / \mathrm{l}$ plus albuminuria & $19.6 \%(218)$ & $19.1 \%(39)$ & 0.8856 \\
\hline eGFR $\left(\mathrm{ml} / \mathrm{min}\right.$ per 1.73 per $\left.\mathrm{m}^{2}\right)$ & $93.6(65.7-117.5)$ & $102.4(86.0-121.0)$ & 0.0002 \\
\hline \multicolumn{4}{|l|}{ Medications during follow-up ${ }^{a}$} \\
\hline Statins & $52.9 \%(590)$ & $27.5 \%(148)$ & $<0.0001$ \\
\hline ACEIs/ARBs & $71.5 \%(797)$ & $53.9 \%(110)$ & $<0.0001$ \\
\hline Insulin & $56.9 \%(643)$ & $52.9 \%(108)$ & 0.2994 \\
\hline Metformin & $68.6 \%(765)$ & $66.7 \%(136)$ & 0.5834 \\
\hline Gliclazide or glibenclamide & $61.1 \%(681)$ & $56.9 \%(116)$ & 0.2578 \\
\hline Rosiglitazone or pioglitazone & $9.8 \%(109)$ & $4.4 \%(9)$ & 0.0136 \\
\hline \multicolumn{4}{|l|}{ Events during follow-up } \\
\hline Hepatocellular carcinoma & $0.72 \%(8)$ & $7.4 \%(15)$ & $<0.0001$ \\
\hline Death & $16.1 \%(180)$ & $11.3 \%(23)$ & 0.0764 \\
\hline \multicolumn{4}{|l|}{ Cirrhosis } \\
\hline At baseline & $0 \%(0)$ & $0.1 \%(1)$ & 0.1547 \\
\hline During follow-up & $0.9 \%(10)$ & $5.4 \%(11)$ & $<0.0001$ \\
\hline Either of them & $0.9 \%(10)$ & $5.8 \%(12)$ & $<0.0001$ \\
\hline
\end{tabular}

HBsAg, hepatitis B surface antigen; LDLC, LDL cholesterol; HDLC, HDL cholesterol; BP, blood pressure; ACR, spot urine albumin:creatinine ratio; eGFR, estimated glomerular filtration rate; ACEls, angiotensin-converting enzyme inhibitors; ARBs, angiotensin II receptor blockers; HBV, hepatitis B virus.

${ }^{a}$ Drug use during follow-up was defined as drug use in the period from enrollment to the first hepatocellular carcinoma event, death, or 30 July 2005 , whichever came first.

the two drugs were calculated, using a logistic regression procedure with stepwise selection of variables at enrollment $(P<0.30$ for entry and stay; Yang et al. $2012 d)$. The two propensity scores were used in the second adjustment scheme in both analyses. This study considered $P$ values below 0.05 to be statistically significant.

\section{Results}

\section{Clinical characteristics}

Patients with HBsAg assay results had worse glucose and lipid control and renal function and were more likely to have cirrhosis than those without HBsAg status. The former were more likely to use insulin, statins, and angiotensin-converting enzyme inhibitors/angiotensin II receptor blockers but less likely to use oral antidiabetes drugs including metformin. They were more likely to develop HCC and die (Table 1).

Patients with positive HBsAg had a median age of 52 (25th-75th percentile: $46-62$ ) years. During 5782 years of follow-up, $1.74 \%(n=23)$ developed HCC with an annual incidence of 3.98 (95\% CI, 2.36-5.60)/1000 person-years. Patients with positive HBsAg status were younger, had lower LDLC and TG, and less likely to use statins and 
Table 3 HRs of carrier status of HBsAg for the risk of HCC in relation to HbA1c in type 2 diabetes.

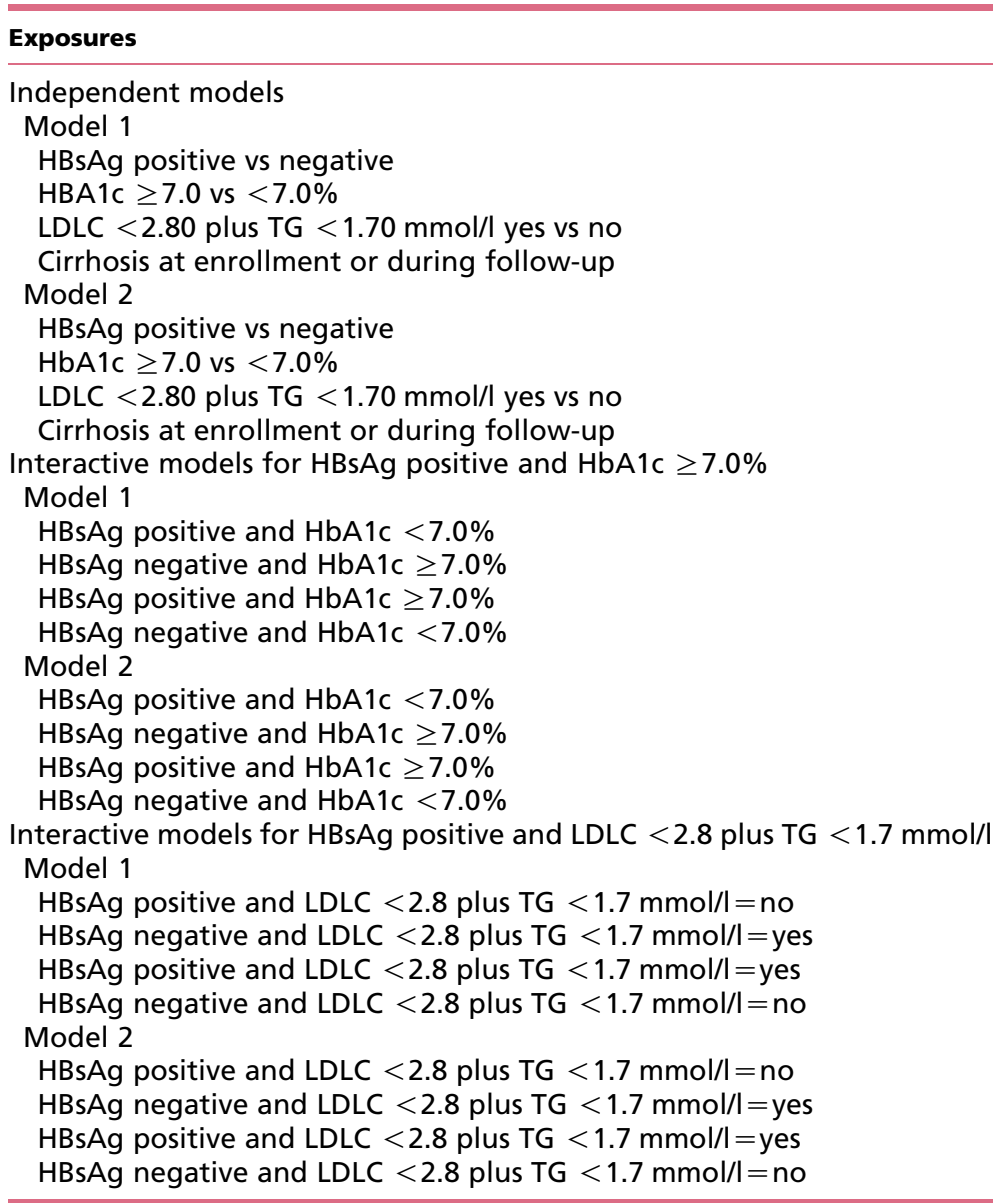

HCC (\%)

HR

$95 \% \mathrm{Cl}$ of HR

$P$ value

$\begin{array}{crlr}15(7.35 \%) & 9.17 & 3.47-24.28 & <0.0001 \\ 18(2.18 \%) & 1.73 & 0.63-4.73 & 0.2884 \\ 15(4.73 \%) & 3.92 & 1.55-9.95 & 0.0040 \\ 3(13.64 \%) & 2.15 & 0.50-9.22 & 0.3035 \\ & & & \\ 15(7.35 \%) & 11.36 & 3.74-34.46 & <0.0001 \\ 18(2.18 \%) & 8.73 & 1.75-43.60 & 0.0083 \\ 15(4.73 \%) & 8.74 & 2.36-32.37 & 0.0012 \\ 3(13.64 \%) & 3.16 & 0.71-14.05 & 0.1311\end{array}$

\begin{tabular}{crcr}
$2(2.60 \%)$ & 5.12 & $0.81-32.30$ & 0.0826 \\
$5(0.72 \%)$ & 0.90 & $0.21-3.79$ & 0.8878 \\
$13(10.24 \%)$ & 16.00 & $\begin{array}{c}4.27-59.89 \\
\text { Reference }\end{array}$ & $<0.0001$ \\
$3(0.72 \%)$ & & & \\
& & & \\
$2(2.60 \%)$ & 3.74 & $0.56-25.06$ & 0.1736 \\
$5(0.72 \%)$ & 4.25 & $0.70-25.74$ & 0.1158 \\
$13(10.24 \%)$ & 74.96 & $\begin{array}{c}10.79-520.71 \\
\text { Reference }\end{array}$ & $<.0001$ \\
$3(0.72 \%)$ & \multicolumn{3}{c}{}
\end{tabular}

\begin{tabular}{crcr}
$4(3.28 \%)$ & 10.75 & $2.58-44.73$ & 0.0011 \\
$4(1.70 \%)$ & 4.43 & $1.08-18.09$ & 0.0382 \\
$11(13.41 \%)$ & 39.11 & $11.39-134.77$ & $<0.0001$ \\
$4(0.75 \%)$ & \multicolumn{3}{c}{ Reference } \\
& & \\
$4(3.28 \%)$ & 11.01 & $2.37-51.14$ & 0.0022 \\
$4(1.70 \%)$ & 8.17 & $1.44-46.29$ & 0.0177 \\
$11(13.41 \%)$ & 89.82 & $17.60-458.35$ & $<0.0001$ \\
$4(0.75 \%)$ & \multicolumn{3}{c}{ Reference }
\end{tabular}

HR, hazard ratio; Cl, confidence interval; TG, triglyceride; HBsAg, hepatitis B surface antigen; HCC, hepatocellular carcinoma. Model 1: adjusted for age sex, intake of tobacco (ex-smoker and current smoker) and alcohol (ex-drinker and current drinker), BMI ( $<24$ and $\geq 27.6 \mathrm{~kg} / \mathrm{m}^{2}$ ), and cirrhosis. Model 2: further adjusted for LDLC-related risk indicators (LDLC $<2.80 \mathrm{mmol} / \mathrm{l}$ plus albuminuria or plus TG $<1.70 \mathrm{mmol} / \mathrm{l}$ and LDLC $\geq 3.80 \mathrm{mmol} / \mathrm{l}$ where appropriate), $\mathrm{HDLC}$ $(<1.0$ and $\geq 1.3 \mathrm{mmol} / \mathrm{l})$, systolic BP, as well as use of statins, RAS inhibitors (ACEls or ARBs), insulin, metformin, glibenclamide/gliclazide, and rosiglitazone/pioglitazone during follow-up period.

more likely to develop HCC than those with negative HBsAg status (Table 2).

\section{Enhancers of the effect of chronic HBV infection on HCC}

Chronic HBV infection, HbA1c $\geq 7 \%$, and co-presence of low LDLC plus low TG were independently associated with higher HRs for HCC (Table 3). On multivariable analysis, HbA1c $\geq 7 \%$ greatly increased the HR of positive HBsAg for HCC from 3.74 to 74.96 (Table 3) with significant additive interaction (AP: 0.91; Table 4). Similarly, co-presence of low LDLC plus low TG greatly increased the HR of HBsAg for HCC from 11.01 to 89.82 (Table 3) with significant additive interaction (AP: 0.80; Table 4). Figure $1 \mathrm{~A}$ and B showed the adjusted cumulative incidences of HCC stratified by various combinations of chronic HBV infection, HbA1c $\geq 7 \%$, or co-presence of low LDLC plus low TG.

\section{Attenuators of the effect of HBV infection on HCC}

In multivariable analysis, use of insulin attenuated the HR of HBsAg for HCC from 37.51 to 5.87 (Table 5) with significant additive interaction (AP: 0.80; Table 4). Similarly, use of statins attenuated the HR of HBsAg for HCC from 64.94 to 16.99 (Table 5) with significant additive interaction (AP: 0.67; Table 4). Figure 1C and D showed the adjusted cumulative incidences of HCC stratified by various combinations of HBV infection, insulin, or statins use.

\section{Additional analysis on cirrhosis status}

We compared the clinical profile of patients with cirrhosis and those without. Patients with cirrhosis had higher HDLC and were less likely to be treated with statins and metformin but more likely to be treated with insulin in multivariable analysis (data not shown).

Published by Bioscientifica Ltd 
Table 4 Additive interactions of HBsAg carrier status with enhancers and alleviators for HCC in type 2 diabetes.

\begin{tabular}{|c|c|c|c|}
\hline $\begin{array}{l}\text { Measures of } \\
\text { additive } \\
\text { interaction }\end{array}$ & Estimate & 95\% Cl & $P$ value* \\
\hline \multirow{2}{*}{\multicolumn{4}{|c|}{$\begin{array}{l}\text { Interaction between HBsAg positive and } \mathrm{HbA} 1 \mathrm{c} \geq 7.0 \% \\
\text { Model } 1\end{array}$}} \\
\hline & & & \\
\hline RERI & 10.98 & -5.70 to 27.66 & 0.1698 \\
\hline AP & 0.69 & 0.20 to 1.18 & 0.0062 \\
\hline \multicolumn{4}{|l|}{ Model 2} \\
\hline RERI & 67.97 & -68.87 to 204.82 & 0.3303 \\
\hline AP & 0.91 & 0.78 to 1.04 & $<0.0001$ \\
\hline \multirow{2}{*}{\multicolumn{4}{|c|}{$\begin{array}{l}\text { Interaction between HBsAg positive and LDLC }<2.8 \mathrm{mmol} \text { plus } \\
\text { TG }<1.7 \mathrm{mmol} / \mathrm{l} \\
\text { Model } 1\end{array}$}} \\
\hline & & & \\
\hline RERI & 24.93 & -13.12 to 62.99 & 0.1991 \\
\hline AP & 0.64 & 0.26 to 1.02 & 0.0010 \\
\hline \multicolumn{4}{|l|}{ Model 2} \\
\hline RERI & 71.64 & -21.82 to 165.11 & 0.1330 \\
\hline AP & 0.80 & 0.61 to 0.98 & $<0.0001$ \\
\hline \multicolumn{4}{|c|}{ Interaction between HBsAg positive and nonuse of insulin } \\
\hline \multicolumn{4}{|l|}{ Model 1} \\
\hline RERI & 21.43 & -21.22 to 64.08 & 0.3247 \\
\hline AP & 0.69 & 0.22 to 1.16 & 0.0038 \\
\hline \multicolumn{4}{|l|}{ Model 2} \\
\hline RERI & 29.94 & -42.64 to 102.51 & 0.4187 \\
\hline AP & 0.80 & 0.42 to 1.18 & $<0.0001$ \\
\hline \multicolumn{4}{|c|}{ Interaction between HBsAg positive and nonuse of statins } \\
\hline \multicolumn{4}{|c|}{ Model 1} \\
\hline RERI & 39.09 & -51.40 to 129.67 & 0.3972 \\
\hline AP & 0.68 & 0.15 to 1.21 & 0.0115 \\
\hline \multicolumn{4}{|l|}{ Model 2} \\
\hline RERI & 43.67 & -79.86 to 167.21 & 0.4884 \\
\hline AP & 0.67 & 0.04 to 1.31 & 0.0384 \\
\hline
\end{tabular}

RERI, relative excess risk due to interaction; $A P$, attributable proportion due to interaction; HBsAg, hepatitis B surface antigen; $\mathrm{HCC}$, hepatocellular carcinoma. Models 1 and 2 were adjusted for the same covariates as in Tables 3 and 5. *Statistically significant with RERI $>0$ or AP $>0$ indicating additive interaction.

\section{Discussion}

In this prospective cohort of patients with $\mathrm{T} 2 \mathrm{D}$, we reported for the first time that suboptimal glycemic control (HBA1c $\geq 7 \%$ ) and co-presence of low LDLC plus low TG markedly enhanced the effect of HBV infection on the risk of HCC while use of insulin or statins attenuated the effect, even after adjustment for cirrhosis. HBV infection is a well-established risk factor for HCC, although the underlying molecular mechanisms and pathways remain to be defined (Pan et al. 2011). Recent studies have established that diabetes is strongly associated with increased risk of HCC (El-Serag et al. 2006). In an observational study, the authors reported a synergistic effect between diabetes and HBV infection on the risk of incident HCC (Ko et al. 2012). In this study, suboptimal glycemic control markedly enhanced the risk association between chronic HBV infection and HCC while use of insulin attenuated the risk. These findings reaffirmed the report from a Japanese study where the researchers showed a marked increase in the number and size of liver tumors in insulin-deficient and hyperglycemic animals that was attenuated by insulin (Yamasaki et al. 2010).

In connection with these novel findings, we had reported a synergistic effect of LDLC $<2.80 \mathrm{mmol} / \mathrm{l}$ plus albuminuria on the overall cancer risk in T2D (Yang et al. $2009 a$ ), which was further enhanced by the presence of HDLC $\geq 1.30 \mathrm{mmol} / \mathrm{l}$ (Yang et al. 2012c). In a recent review article, based on a large body of clinical and experimental findings, we hypothesized that these epidemiological findings might reflect increased oxidative stress and upregulation of the RAS activity, secondary to hyperglycemia (Yang et al. 2012b) with inflammation (Yang et al. 2010c) and/or dysregulated cholesterol metabolism (Yang et al. 2009b) as mediating pathways. In this study, we did not detect significant interaction of co-presence of low LDLC plus albuminuria with HBsAg for HCC. On the other hand, we found markedly an enhancing effect of lack of insulin treatment and HBA1c $\geq 7 \%$ on the risk association between HBV infection and HCC, suggesting that insulin insufficiency might be a major culprit in the development of HCC in T2D.

In a large matched case-control study from the USA, use of statins among patients with diabetes was associated with a $26 \%$ reduction in the HCC risk (El-Serag et al. 2009). In another large population-based cohort study from Taiwan, use of statins in HBV-infected patients was associated with a reduced risk for HCC in a dosedependent manner (Tsan et al. 2012). Our study further shows that use of statins might have particular benefits in reducing HCC risk among patients with both T2D and HBV infection. Previously, we reported that low TG was associated with increased overall cancer risk in T2D, which was attenuated by use of statins (Yang et al. 2011a). Further exploration indicated that only co-presence of low TG plus low LDLC and neither of these two factors alone was associated with increased overall cancer risk in T2D (Yang et al. 2012a). Of note, insulin selectively activates SREBP1c, leading to upregulated synthesis of free fatty acids (Shimomura et al. 1999), while IGF1 activates SREBP1a, resulting in upregulated synthesis of both cholesterol and free fatty acids (Smith et al. 2008). As there is a feedback regulation loop from intracellular low cholesterol to IGF1 and SREBP1a to upregulate cholesterol synthesis (Brown \& Goldstein 1997), we hypothesized that insulin insufficiency might lead to low

Published by Bioscientifica Ltd. 

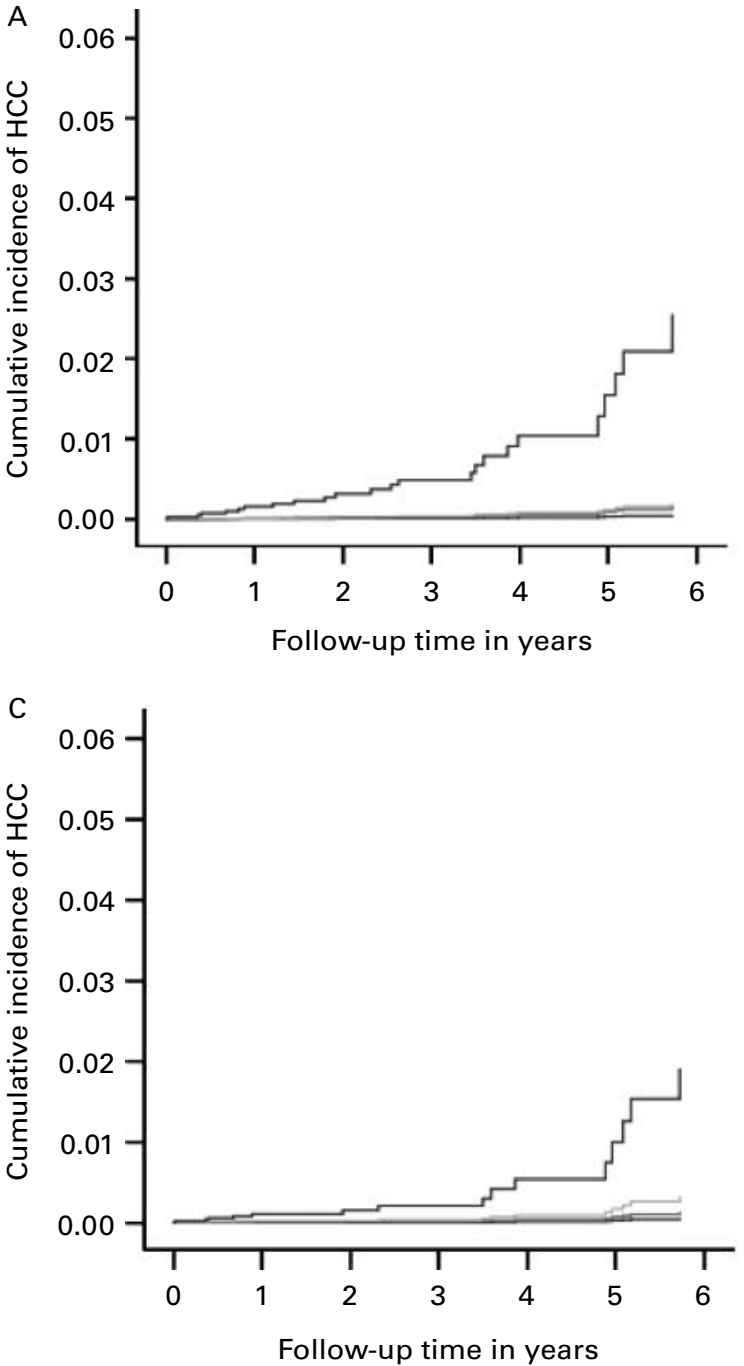

B

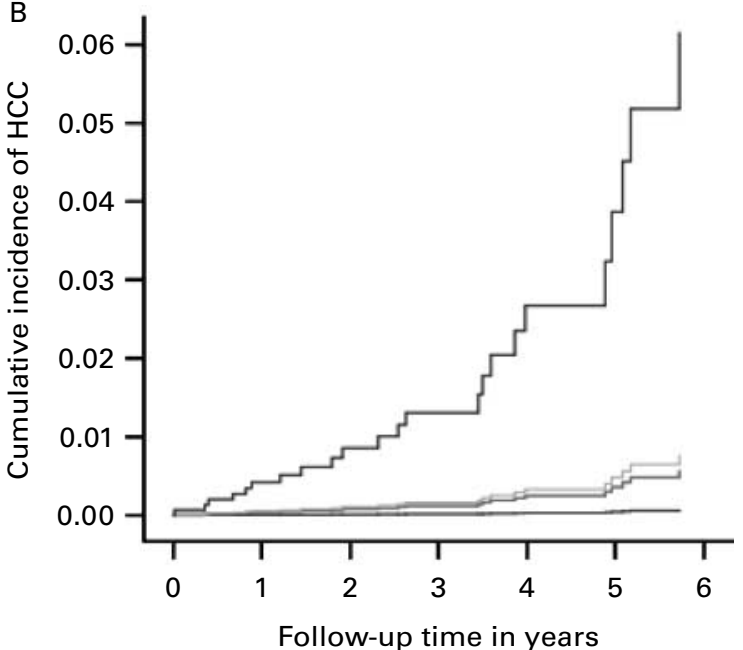

D

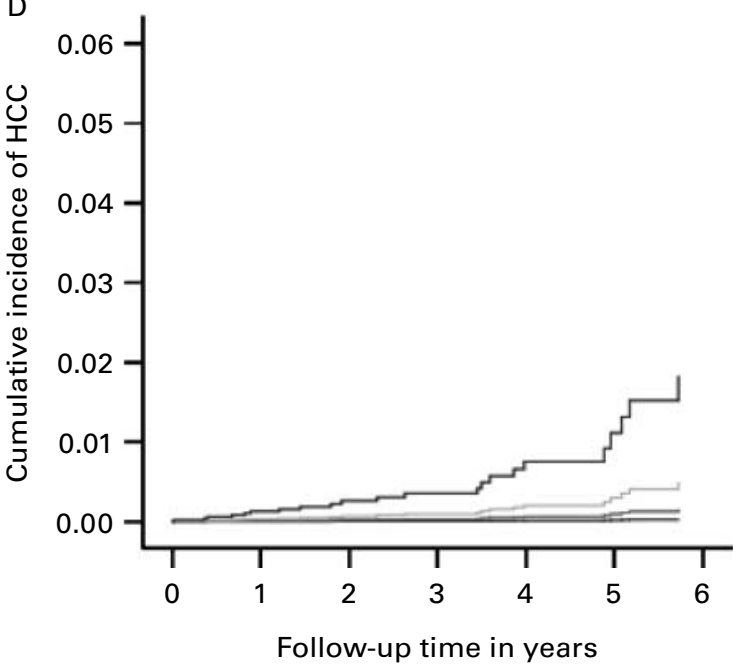

Figure 1

Adjusted cumulative incidence of hepatocellular carcinoma (HCC) stratified by combinations of HBsAg and enhancers or attenuators of its effect on the risk of HCC. (A) From top to bottom: i) HBsAg positive and HbA1c $\geq 7.0 \%$ (top line); ii) HBsAg positive and $\mathrm{HbA} 1 \mathrm{C}<7.0 \%$; iii) $\mathrm{HBsAg}$ negative and $\mathrm{HbA} 1 \mathrm{C} \geq 7.0 \%$; and iv) HBsAg negative and $\mathrm{HbA} 1 \mathrm{c}<7.0 \%$ (bottom line). (B) From top to bottom: i) HBsAg positive and LDLC $<2.8 \mathrm{mmol} / \mathrm{l} \mathrm{plus}$ triglyceride $<1.7 \mathrm{mmol} / \mathrm{l}=$ yes (top line); ii) HBsAg positive and LDLC $<2.8 \mathrm{mmol} / \mathrm{l}$ plus triglyceride $<1.7 \mathrm{mmol} / \mathrm{l}=\mathrm{no}$; iii) $\mathrm{HBsAg}$ negative and LDLC $<2.8 \mathrm{mmol} / \mathrm{l}$ plus triglyceride $<1.7 \mathrm{mmol} / \mathrm{l}=$ yes; and iv) HBsAg negative and LDLC $<2.8 \mathrm{mmol} / \mathrm{l}$ plus triglyceride $<1.7 \mathrm{mmol} / \mathrm{I}=$ no (bottom line). (C) From top to bottom: $\mathrm{i}$ ) $\mathrm{HBsAg}$ positive and nonuse of insulin (top line); ii) HBsAg positive and use of insulin; iii) HBsAg negative and nonuse of insulin; and iv) HBsAg negative and use of insulin (bottom line). (D) From top to bottom: i) HBsAg positive and nonuse of statins (top line); ii) HBsAg positive and use of statins; iii) HBsAg negative and nonuse of statins; and iv) HBsAg negative and use of statins (bottom line). The covariates adjusted and $P$ values are the same as in Tables 3 and 5 .

TG and low LDLC resulting in dysregulation of the IGF1, SREBP1a, and cholesterol synthesis. The activation of the cholesterol pathway can increase RAS signals and other oncogenes resulting in increased cancer risk (Yang et al. $2012 b$ ). In this connection, the enhanced effect of HBV infection on HCC risk by co-presence of low LDLC plus low TG and its attenuation by use of insulin or statins strongly supported our hypothesis. Of note, the residual effects of either HBV infection or co-presence of low LDLC plus low TG remained substantial after controlling for their synergistic effect on the risk of HCC. Use of insulin or statins failed to attenuate the increased HRs for HCC to a level close to 1 . These observations suggested while the pathway from HBV infection to HCC and that from insulin insufficiency to dysregulated cholesterol synthesis were distinct entities, there might be cross talks between them with dysregulated intermediary metabolisms enhancing the promoting effect of chronic HBV infection on HCC. In this regard, recent studies have shown that diabetes could accelerate formation and accumulation of

Published by Bioscientifica Ltd. 
Table 5 Hazard ratios (HRs) of carrier status of HBsAg for the risk of HCC in relation to co-presence of low LDLC and low triglyceride, insulin, and statin usage.

Exposures
Interactive models for HBsAg positive and nonuse of insulin
( 460 subjects who ever used insulin in 2.5 years before enrollment
were excluded)
Model 1
HBsAg positive and use of insulin
HBsAg negative and nonuse of insulin
HBsAg positive and nonuse of insulin
HBsAg negative and use of insulin
Model 2
HBsAg positive and use of insulin
HBsAg negative and nonuse of insulin
HBsAg positive and nonuse of insulin
HBsAg negative and use of insulin
Interactive models for HBsAg positive and nonuse of statins
(264 subjects who ever used statins in 2.5 years before enrollment
were excluded)
Model 1
HBsAg positive and use of statins
HBsAg negative and nonuse of statins
HBsAg positive and nonuse of statins
HBsAg negative and use of statins
Model 2
HBsAg positive and use of statins
HBsAg negative and nonuse of statins
HBsAg positive and nonuse of statins
HBsAg negative and use of statins

HCC (\%) HR

95\% $\mathrm{Cl}$ of $\mathbf{H R}$

$P$ value

$\begin{array}{lllr}2(4.55 \%) & 7.82 & 0.98-62.37 & 0.0522 \\ 5(1.11 \%) & 2.74 & 0.52-14.32 & 0.2331 \\ 6(6.38 \%) & 30.99 & \begin{array}{c}5.56-172.60 \\ \text { Reference }\end{array} & <0.0001 \\ 2(0.74 \%) & & & \\ & & & \\ 2(4.55 \%) & 5.87 & 0.52-66.11 & 0.1522 \\ 5(1.11 \%) & 2.70 & 0.36-20.52 & 0.3375 \\ 6(6.38 \%) & 37.51 & 4.11-342.31 & 0.0013 \\ 2(0.74 \%) & & \text { Reference }\end{array}$

$\begin{array}{rlll}1(2.86 \%) & 13.64 & 0.84-221.23 & 0.0660 \\ 7(1.35 \%) & 5.49 & 0.67-45.15 & 0.1134 \\ 13(8.90 \%) & 57.22 & \begin{array}{l}6.95-470.96 \\ \text { Reference }\end{array} & 0.0002 \\ 1(0.28 \%) & & & \\ 1(2.86 \%) & 16.99 & 0.90-320.98 & 0.0588 \\ 7(1.35 \%) & 5.27 & 0.52-53.92 & 0.1612 \\ 13(8.90 \%) & 64.94 & \begin{array}{c}5.59-754.12 \\ \text { Reference }\end{array} & 0.0009 \\ 1(0.28 \%) & & \end{array}$

$\mathrm{HR}$, hazard ratio; $\mathrm{Cl}$, confidence interval; $\mathrm{HBsAg}$, hepatitis $\mathrm{B}$ surface antigen; $\mathrm{HCC}$, hepatocellular carcinoma. Model 1: adjusted for age sex, intake of tobacco (ex-smoker and current smoker) and alcohol (ex-drinker and current drinker), BMI ( $<24$ and $\geq 27.6 \mathrm{~kg} / \mathrm{m}^{2}$ ), and cirrhosis. Model 2: further adjusted for LDLC related risk indicators (LDLC $<2.80 \mathrm{mmol} / /$ plus albuminuria or plus TG $<1.70 \mathrm{mmol} / \mathrm{l}$ and LDLC $\geq 3.80 \mathrm{mmol} / / \mathrm{l}$ where appropriate), HDLC ( $<1.0$ and $\geq 1.3 \mathrm{mmol} / \mathrm{l}$ ), systolic BP, as well as use of statins, RAS inhibitors (ACEls or ARBs), insulin, metformin, glibenclamide/gliclazide, and rosiglitazone/pioglitazone during follow-up period as well as the propensity score for use of insulin (the $c$-statistic $=0.78$ ) or statins (the $c$-statistic $=0.81$ ) during follow-up period where appropriate.

advanced glycation end products (AGEs), which have been implicated in development of liver disease (Hyogo \& Yamagishi 2008). Further experimental studies are needed to study the effects of AGEs on promoting HBV-associated HCC risk in diabetes.

\section{Study limitations}

There are several limitations of this study. First, this study had a small sample size with only 23 cases of HCC, which resulted in wide confidence intervals. However, due to the large effect sizes of variables of interest, we were able to detect highly significant enhancers and attenuators of HBV infection on the risk of HCC. Although the final models were overfitted, the relatively constant HRs derived in both the minimally and the fully adjusted models suggested that the impact of overfitting on the effect sizes was small, if any.

Second, there might be a selection bias as not every patient in the cohort had HBsAg measurements. Patients with HBsAg measurement had worse glucose control and renal functions and were more likely to have HCC and to die. Therefore, findings from this analysis could not be extrapolated to low-risk populations with T2D.

Third, this was an observational study with inherent biases, which could not be completely removed despite statistical adjustments. Thus, these results only generated hypotheses for further testing and should not influence clinical practice. Besides, a small number of patients who had negative HBsAg but positive hepatitis B core antigen might have been misclassified.

Finally, liver function at enrollment was not available for analysis. We acknowledged that cirrhosis might contribute to the lipid pattern of low LDLC and low TG, for example, due to poor nutrition. However, we did not observe differences in BMI or distribution of co-presence of low LDLC and low TG between patients with or without cirrhosis. Up to $31.5 \%(n=415)$ of patients in the cohort had co-presence of low LDLC and low TG and 97.3\% $(n=404)$ of patients with this phenotype did not have

Published by Bioscientifica Ltd. 
cirrhosis, although $50 \%(n=11)$ of patients with cirrhosis had this cancer risk phenotype and $27.3 \%(n=6)$ of them had low BMI defined as BMI $<24 \mathrm{~kg} / \mathrm{m}^{2}$. Besides, adjustment for cirrhosis tended to increase the HR of co-presence of low LDLC and low TG for HCC from 7.20 (95\% CI, 1.82-28.48) to 8.74 (95\% CI, 2.36-32.37; Table 3, independent models, model 2). Taken together, the association between HCC and co-presence of low LDLC and low TG was unlikely due to cirrhosis or its metabolic consequences.

\section{Conclusion}

In conclusion, in Chinese T2D patients with known HBsAg status, suboptimal glycemic control (HbA1c $\geq 7 \%)$ and co-presence of low LDLC plus low TG greatly enhanced the promoting effect of chronic HBV infection on HCC, while use of insulin or statins attenuated the increased risk. These observations support the notion that upregulation of the IGF1, SREBP1a, and cholesterol synthesis pathway due to insulin insufficiency might link diabetes and HCC and that dysregulation of these interlinked pathways might markedly enhance the promoting effect of chronic HBV infection on HCC in T2D. Given the high prevalence of T2D and HCC as well as the poor prognosis of patients with HCC, there is an urgent need to replicate these novel findings in separate cohorts and to investigate the underlying molecular mechanisms. As insulin and statins are safe and widely used in T2D, we also call for randomized clinical trials to test whether use of insulin and statins in T2D patients who are carriers of $\mathrm{HBV}$ and risk-conferring phenotypes will reduce the risk of HCC.

\section{Declaration of interest}

J C N Chan has received research grant and/or honorarium for consultancy or giving lectures from Bayer, Daiichi-Sankyo, Lilly, GlaxoSmithKline, Merck Sharp \& Dohme, Merck Serono, Pfizer, Astra Zeneca, Sanofi-Aventis, Novo-Nordisk, and/or Bristol-Myers Squibb. A P S Kong has received honorarium for consultancy or giving lectures from Merck Serono and Lilly. $\mathrm{G}$ Xu has received research grant and/or honorarium for consultancy or giving lectures from Merck Sharp \& Dohme. R C W Ma has received honorarium for consultancy or giving lectures from Boehringer-Ingelheim, Eli Lilly, Astra-Zeneca, Danone, Nestle, and Pfizer. All proceeds have been donated to the Chinese University of Hong Kong to support the ongoing research. Other authors declared no conflict of interest with this manuscript.

\section{Funding}

This study was supported by a Research Grants Council Direct Allocation (reference no. 2009.2.010) and the Hong Kong Foundation for Research and Development in Diabetes, Lioa Wun Yuk Diabetes Memorial Fund, established under the auspices of the Chinese University of Hong Kong. $X$ Yang and J C N Chan are the guarantors of this manuscript.

\section{Acknowledgements}

The authors thank all medical and nursing staff of the Diabetes and Endocrine Centre of the Prince of Wales Hospital for recruiting and managing these patients.

\section{References}

American Diabetes Association 2012 Standards of medical care in diabetes 2012. Diabetes Care 35 (Suppl 1) S11-S63. (doi:10.2337/dc12-s011)

Andersson T, Alfredsson L, Kallberg H, Zdravkovic S \& Ahlbom A 2005 Calculating measures of biological interaction. European Journal of Epidemiology 20 575-579. (doi:10.1007/s10654-005-7835-x)

Brown MS \& Goldstein JL 1997 The SREBP pathway: regulation of cholesterol metabolism by proteolysis of a membrane-bound transcription factor. Cell 89 331-340. (doi:10.1016/S0092-8674(00)80213-5)

Burrel M, Reig M, Forner A, Barrufet M, de Lope CR, Tremosini S, Ayuso C, Llovet JM, Real MI \& Bruix J 2012 Survival of patients with hepatocellular carcinoma treated by transarterial chemoembolisation (TACE) using drug eluting beads. Implications for clinical practice and trial design. Journal of Hepatology 56 1330-1335. (doi:10.1016/j.jhep. 2012.01.008)

Chan JC, Malik V, Jia W, Kadowaki T, Yajnik CS, Yoon KH \& Hu FB 2009 Diabetes in Asia: epidemiology, risk factors, and pathophysiology. Journal of the American Medical Association 301 2129-2140. (doi:10.1001/jama.2009.726)

De Mitri MS, Cassini R \& Bernardi M 2010 Hepatitis B virus-related hepatocarcinogenesis: molecular oncogenic potential of clear or occult infections. European Journal of Cancer 46 2178-2186. (doi:10.1016/ j.ejca.2010.03.034)

El-Serag HB, Hampel H \& Javadi F 2006 The association between diabetes and hepatocellular carcinoma: a systematic review of epidemiologic evidence. Clinical Gastroenterology and Hepatology 4 369-380. (doi:10.1016/j.cgh.2005.12.007)

El-Serag HB, Johnson ML, Hachem C \& Morgana RO 2009 Statins are associated with a reduced risk of hepatocellular carcinoma in a large cohort of patients with diabetes. Gastroenterology 136 1601-1608. (doi:10.1053/j.gastro.2009.01.053)

Everhart J \& Wright D 1995 Diabetes mellitus as a risk factor for pancreatic cancer. A meta-analysis. Journal of the American Medical Association 273 1605-1609. (doi:10.1001/jama.1995.03520440059037)

Forner A, Llovet JM \& Bruix J 2012 Hepatocellular carcinoma. Lancet 379 1245-1255. (doi:10.1016/S0140-6736(11)61347-0)

Friedewald WT, Levy RI \& Fredrickson DS 1972 Estimation of the concentration of low-density lipoprotein cholesterol in plasma, without use of the preparative ultracentrifuge. Clinical Chemistry 18 499-502.

Hyogo H \& Yamagishi S 2008 Advanced glycation end products (AGEs) and their involvement in liver disease. Current Pharmaceutical Design 14 969-972. (doi:10.2174/138161208784139701)

Ko WH, Chiu SY, Yang KC \& Chen HH 2012 Diabetes, hepatitis virus infection and hepatocellular carcinoma: a case-control study in hepatitis endemic area. Hepatology Research 42 774-781. (doi:10.1111/ j.1872-034X.2012.00979.x)

Laakso M \& Pyorala K 1985 Age of onset and type of diabetes. Diabetes Care 8 114-117. (doi:10.2337/diacare.8.2.114)

Li R \& Chambless L 2007 Test for additive interaction in proportional hazards models. Annals of Epidemiology 17 227-236. (doi:10.1016/ j.annepidem.2006.10.009)

Ma YC, Zuo L, Chen JH, Luo Q, Yu XQ, Li Y, Xu JS, Huang SM, Wang LN, Huang W et al. 2006 Modified glomerular filtration rate estimating equation for Chinese patients with chronic kidney disease. Journal of the American Society of Nephrology 17 2937-2944. (doi:10.1681/ASN. 2006040368) 
Pan H, Fu X \& Huang W 2011 Molecular mechanism of liver cancer. Anti-Cancer Agents in Medicinal Chemistry 11 493-499. (doi:10.2174/ 187152011796011073)

Piwernetz K, Home PD, Snorgaard O, Antsiferov M, Staehr-Johansen K \& Krans M, For the DiabCare Monitoring Group of the St. Vincent Declaration Steering Committee 1993 Monitoring the targets of the St. Vincent declaration and the implementation of quality management in diabetes care: the DiabCare initiative. Diabetic Medicine 10 371-377. (doi:10.1111/j.1464-5491.1993.tb00083.x)

Shimomura I, Bashmakov Y, Ikemoto S, Horton JD, Brown MS \& Goldstein JL 1999 Insulin selectively increases SREBP-1c mRNA in the livers of rats with streptozotocin-induced diabetes. PNAS 96 13656-13661. (doi:10.1073/pnas.96.24.13656)

Smith TM, Gilliland K, Clawson GA \& Thiboutot D 2008 IGF-1 induces SREBP-1 expression and lipogenesis in SEB-1 sebocytes via activation of the phosphoinositide 3-kinase/Akt pathway. Journal of Investigative Dermatology 128 1286-1293. (doi:10.1038/sj.jid.5701155)

Tsan YT, Lee CH, Wang JD \& Chen PC 2012 Statins and the risk of hepatocellular carcinoma in patients with hepatitis B virus infection. Journal of Clinical Oncology 30 623-630. (doi:10.1200/JCO.2011.36. 0917)

Wang Y \& Jia J 2011 Control of hepatitis B in China: prevention and treatment. Expert Review of Anti-Infective Therapy 9 21-25. (doi:10.1586/ eri.10.143)

Yamasaki K, Hayashi Y, Okamoto S, Osanai M \& Lee GH 2010 Insulinindependent promotion of chemically induced hepatocellular tumor development in genetically diabetic mice. Cancer Science 101 65-72. (doi:10.1111/j.1349-7006.2009.01345.x)

Yang X, So WY, Ma RC, Ko GT, Kong AP, Wang Q, Cockram CS, Chow CC, Chan JC \& Tong PC 2008a Predicting values of lipids and white blood cell count for all-site cancer in type 2 diabetes. Endocrine-Related Cancer 15 597-607. (doi:10.1677/ERC-07-0266)

Yang X, So WY, Tong PC, Ma RC, Kong AP, Lam CW, Ho CS, Cockram CS, Ko GT, Chow CC et al. $2008 b$ Development and validation of an all-cause mortality risk score in type 2 diabetes. Archives of Internal Medicine 168 451-457. (doi:10.1001/archinte.168.5.451)

Yang X, So WY, Ma RC, Ko GT, Kong AP, Zhao H, Luk AO, Lam CW, Ho CS, Tong PC et al. 2009a Low LDL cholesterol, albuminuria, and statins for the risk of cancer in type 2 diabetes: the Hong Kong Diabetes Registry. Diabetes Care 32 1826-1832. (doi:10.2337/dc09-0725)

Yang X, Zhao H, Sui Y, Ma RC, So WY, Ko GT, Kong AP, Ozaki R, Yeung CY, $\mathrm{Xu} \mathrm{G}$ et al. 2009b Additive interaction between the renin-angiotensin system and lipid metabolism for cancer in type 2 diabetes. Diabetes $\mathbf{5 8}$ 1518-1525. (doi:10.2337/db09-0105)

Yang X, Ko GT, So WY, Ma RC, Yu LW, Kong AP, Zhao H, Chow CC, Tong PC \& Chan JC 2010a Associations of hyperglycemia and insulin usage with the risk of cancer in type 2 diabetes: the Hong Kong Diabetes Registry. Diabetes 59 1254-1260. (doi:10.2337/db09-1371)

Yang W, Lu J, Weng J, Jia W, Ji L, Xiao J, Shan Z, Liu J, Tian H, Ji Q et al. $2010 b$ Prevalence of diabetes among men and women in China. New England Journal of Medicine 362 1090-1101. (doi:10.1056/ NEJMoa0908292)

Yang X, Ma RC, So WY, Ko GT, Kong AP, Zhao H, Xu G, Tong PC \& Chan JC $2010 c$ White blood cell count and renin-angiotensin system inhibitors for the risk of cancer in type 2 diabetes. Diabetes Research and Clinical Practice 87 117-125. (doi:10.1016/j.diabres.2009.10.012)

Yang X, So WY, Ma RC, Yu LW, Ko GT, Kong AP, Ng VW, Luk AO, Ozaki R, Tong PC et al. $2010 d$ Use of sulphonylurea and cancer in type 2 diabetes - the Hong Kong Diabetes Registry. Diabetes Research and Clinical Practice 90 343-351. (doi:10.1016/j.diabres.2010.08.022)

Yang X, Ma RC, So WY, Yu LW, Kong AP, Ko GT, Xu G, Ozaki R, Tong PC \& Chan JC 2011 $a$ Low triglyceride and nonuse of statins is associated with cancer in type 2 diabetes mellitus: the Hong Kong Diabetes Registry. Cancer 117 862-871. (doi:10.1002/cncr.25455)

Yang X, So WY, Ma RC, Kong AP, Lee HM, Yu LW, Chow CC, Ozaki R, Ko GT \& Chan JC $2011 b$ Low HDL cholesterol, metformin use, and cancer risk in type 2 diabetes: the Hong Kong Diabetes Registry. Diabetes Care 34 375-380. (doi:10.2337/dc10-1509)

Yang X, So WY, Ma RC, Kong AP, Lee HM, Xu G, Ozaki R \& Chan JC $2012 a$ Synergistic effects of low LDL cholesterol with other factors for the risk of cancer in type 2 diabetes: the Hong Kong Diabetes Registry. Acta Diabetologia 49 S185-S193. (doi:10.1007/s00592-012-0409-y)

Yang X, So WY, Ma RC, Kong AP, Xu G \& Chan JC 2012b Diabetes and cancer: the mechanistic implications of epidemiological analyses from the Hong Kong Diabetes Registry. Diabetes/Metabolism Research and Reviews 28 379-387. (doi:10.1002/dmrr.2287)

Yang X, So WY, Ma RC, Yu LW, Kong AP, Lee HM, Xu G, Ozaki R, Ko GT \& Chan JC 2012c Use of thiazolidinedione and cancer risk in type 2 diabetes: the Hong Kong Diabetes Registry. Diabetes Research and Clinical Practice 97 e11-e15. (doi:10.1016/j.diabres.2012.03.006)

Yang XL, Ma RC, So WY, Kong AP, Xu G \& Chan JC 2012d Addressing different biases in analysing drug use on cancer risk in diabetes in non-clinical trial settings - what, why and how? Diabetes, Obesity \& Metabolism 14 579-585. (doi:10.1111/j.1463-1326.2011.01551.x)

Received in final form 22 November 2012

Accepted 18 December 2012

Made available online as an Accepted Preprint

18 December 2012 http://erc.endocrinology-journals.org

DOI: 10.1530/ERC-12-0290
(C) 2013 Society for Endocrinology Printed in Great Britain
Published by Bioscientifica Ltd. 